\title{
A REDUÇÃO DAS PRESTAÇÕES ESTATAIS EFETIVADORAS DE DIREITOS SOCIAIS E O PRINCÍPIO DA SEGURANÇA JURÍDICA
}

\author{
Ana Luiza Kubiça Pavão Espindola ${ }^{1}$
}

RESUMO: Em tempos de crises econômico-financeiras, aumenta a procura dos agentes estatais por medidas que impliquem corte de gastos. Mas até que ponto as prestações efetivadoras de direitos sociais podem ser reduzidas sem que isso caracterize uma violação à segurança jurídica e à proteção da confiança legítima? Conduz-se o presente estudo inicialmente como uma pesquisa exploratória e, após, como uma pesquisa explanatória, por meio de uma abordagem qualitativa consubstanciada na pesquisa bibliográfica, que permita aprofundar a compreensão sobre a redução de prestações sociais e sobre a segurança jurídica. Busca-se, ao final, a obtenção de uma resposta para a pergunta acima.

Palavras-chave: Direitos sociais; Políticas públicas; Vedação ao retrocesso social; Segurança jurídica; Proteção da confiança.

\section{SHRINKING SOCIAL PROVISIONS IN SOCIAL RIGHTS MATTER AND THE}

\section{LEGAL CERTAINTY PRINCIPLE}

ABSTRACT: In times of economic-financial crisis, the political discourse increases in the direction of the cut of expenses. But to what extent can benefits that effectively enforce social rights be reduced without it characterizing a violation of legal certainty and the protection of legitimate expectations? The present study is conducted initially as an exploratory research and, in a second moment, as an explanatory one, by a qualitative approach using bibliographic research that allows deepen understanding about the shrinking of social provisions and about the legal certainty principle. It searches, at the end, an answer for the question above.

Keywords: Social rights; Social provisions; Sealing social regression; Legal certainty; Trust protection.

\footnotetext{
${ }^{1}$ Mestranda em Direito Público pela Universidade do Vale do Rio dos Sinos - UNISINOS. Pós-graduanda em Direito do Estado pela Universidade Federal do Rio Grande do Sul - UFRGS. E-mail: espindola.analuiza@gmail.com.

O presente trabalho foi realizado com apoio da Coordenação de Aperfeiçoamento de Pessoal de Nível Superior Brasil (CAPES) - Código de Financiamento 001.
} 


\section{INTRODUÇÃO}

Os direitos sociais, embora previstos constitucionalmente dentro do rol de direitos fundamentais, ainda são alvo de dúvidas por parte da doutrina e da jurisprudência, que questiona a sua fundamentalidade. Considerando a evolução histórica dos direitos de segunda dimensão, percebe-se impossível a concretização de um Estado Democrático de Direito sem a elevação de direitos sociais a direitos fundamentais. Ademais, somente se pode considerar um Estado verdadeiramente democrático quando comprometido com a busca pela dignidade da pessoa humana, a qual não tem como se consubstanciar sem a efetivação de direitos de igualdade.

Todavia, em épocas e Estados que enfrentam crises econômico-financeiras, como as recorrentes atualmente em diversas nações, a redução de prestações positivas, asseguradoras de direitos sociais, costuma se apresentar como uma das principais medidas de retenção de gastos governamentais para adequação a orçamentos restritos. Não raro, essa contenção de despesas é incorporada ao discurso político como essencial à mantença do Estado, e o seu oposto é professado como uma ameaça à estabilidade econômica nacional.

Sob viés oposto, se a concretização de direitos de segunda dimensão depende diretamente de prestação estatal que os assegure, há quem defenda que a redução no fornecimento de serviços sociais constitui ofensa à segurança jurídica, especialmente no seu sentido substantivo, uma vez que gerada uma crença legítima nos cidadãos de que a situação anterior à redução seria mantida. Cabe aqui mencionar a relação genética existente entre a segurança social (no sentido da garantia de direitos sociais e da vida com dignidade) e a segurança jurídica.

Assim, especialmente em momentos de crise e de busca por contenção de gastos públicos, entram em tensão dois discursos fundamentais. A seu turno, setores governamentais defendem que devem ser reduzidos os investimentos em direitos sociais e, assim, assegurar a manutenção do Estado pelos próximos anos. Em contraponto, há o entendimento de que a mitigação de prestações estatais positivas caracteriza a própria falência do Estado, porquanto este se mostra incapaz de atender ao objetivo primordial pelo qual foi criado - conferir segurança jurídica a todos os indivíduos-sujeitos, atendendo parcela de seus direitos essenciais - e, dessa forma, perde a sua legitimidade e razão de existir.

Para buscar uma resposta adequada a esse dilema, realiza-se o presente estudo, mediante pesquisas exploratórias e explanatórias, com auxílio do método qualitativo e da 
técnica de pesquisa bibliográfica, resgatando, inicialmente, as razões históricas da existência dos direitos fundamentais sociais, de onde se extrai o seu compromisso com a garantia de promover a dignidade da pessoa humana e com a legitimidade do Estado.

Em seguida, passa-se a uma análise mais profunda (e ainda exploratória bibliográfica) da segurança jurídica propriamente dita, de suas diversas dimensões e dos seus aspectos relacionados aos direitos sociais, na tentativa de descobrir se reduzir prestações estatais garantidoras de direitos de segunda dimensão implica ofensa à segurança jurídica.

Por fim, para superação do dilema entre aqueles que defendem a redução de prestações sociais em momentos de crise financeira e aqueles que sustentam a continuidade das políticas públicas de natureza social a qualquer custo, procura-se uma solução trazida do direito administrativo e do princípio da segurança jurídica, com alguma adaptação de seu uso tradicional - o que garante a este estudo o seu caráter explanatório.

Assim, propõe-se compreender qual é o limite ao qual a prestação garantidora de direitos sociais pode ser restringida sem que essa providência caracterize uma violação a direitos prestacionais sobre os quais recaía confiança legítima de efetivação, bem como propor uma estratégia mediante a qual se consigam reduzir as prestações necessárias a adequações orçamentárias sem prejuízo à confiança legítima dos cidadãos.

\section{A SEGURANÇA JURÍDICA E OS DIREITOS SOCIAIS: UMA RELAÇÃO NECESSÁRIA NO ESTADO DEMOCRÁTICO DE DIREITO}

Os direitos sociais, prestacionais ou, ainda, direitos de segunda dimensão se desenvolveram a partir da percepção de que o mero direito formal à liberdade, característico de momento histórico anterior, não bastava para assegurar que o cidadão pudesse efetivamente usufruir da liberdade (SARLET; MARINONI; MITIDIERO, p. 314-315). Esse entendimento ganhou mais força a partir das Revoluções Industriais e das graves crises socioeconômicas que as seguiram, pondo em evidência que não se poderia dizer livre um trabalhador que laborava durante 18 horas do seu dia para que não perecesse de fome e que o direito a liberdade, sem auxílio material, era ineficaz para os milhares de indivíduos que se encontravam nessa condição.

A partir daí delinearam-se amplos movimentos reivindicatórios por justiça social, que clamavam pela atuação positiva do Estado, no sentido de propiciar um "direito de participar do bem-estar social” (LAFER, 1988, p. 127). Para tanto, era preciso que o ente 
público realizasse prestações, englobando assistência social, educação, saúde e afins, que garantissem aos cidadãos a fruição de um mínimo de direitos essenciais para uma existência digna.

No período que se seguiu à Segunda Guerra Mundial, a preocupação com os direitos humanos atingiu o seu ápice e se tornou objeto de interesse e preocupação em nível nacional e internacional (PIOVESAN, 2013, p. 65). Naquela época, muitos dos países ocidentais (p.e. Brasil, Itália, Portugal, Alemanha) haviam recém superado regimes totalitários ou autoritários de governo, no mesmo momento em que surgia o entendimento de que um Estado democrático só o é se tem suas bases em direitos fundamentais (VILLIERS, 1992).

A necessidade primordial da época era assegurar a limitação jurídica do poder político (PIOVESAN, 2013, p. 89) para evitar que novos abusos fossem cometidos em favor daqueles que detinham o poder e em detrimento da população em geral. Os direitos fundamentais se caracterizaram, assim, como uma proteção dos indivíduos contra o cometimento de abusos por parte dos que estavam no poder (direito individuais), bem como uma garantia das mínimas condições para uma existência digna (direitos sociais) (CALMON DE PASSOS, 1988, p. 92).

Nessa senda, os movimentos constitucionalistas modernos não conduziram somente ao estabelecimento de extensos catálogos (consoante denominação de José Joaquim Gomes Canotilho, 1992, p. 68) de direitos individuais e sociais nas novas constituições, como também à alocação desses róis na parte inicial do texto constitucional, com estrutura topológica privilegiada reservada aos direitos humanos e garantias fundamentais (SARLET; MARINONI; MITIDIERO, p. 85).

Tal estratégia de posicionamento visa a "enfatizar o papel privilegiado dos princípios estruturantes (princípios fundamentais) e dos direitos e garantias fundamentais" (SARLET; MARINONI; MITIDIERO, p. 85), além de indicar que é o Estado que existe para o ser humano, e não o ser humano que existe para manter o Estado. Ou seja, primeiro importam os direitos fundamentais, sendo a partir destes e para assegurá-los que o aparato estatal deve se organizar. Embora não haja hierarquia formal entre normas constitucionais, certo é que existe uma ordem preferencial de valores dentro das Constituições, ainda que não de maneira explícita.

Considerando a opção do constituinte originário por incluir os direitos sociais dentro do Título II da Constituição Federal e tendo-se em conta que os direitos de segunda dimensão 
encerram em si a mesma função daqueles de primeira dimensão, no sentido de que a atuação estatal deve ser orientada e limitada segundo tais direitos, não há como sustentar que haja abismais diferenças entre os direitos individuais e os sociais. Assim, filia-se aqui ao posicionamento de Ingo Wolfgang Sarlet, para quem os direitos sociais são, também, direitos fundamentais (SARLET; MARINONI; MITIDIERO, p. 601).

Em sentido similar, Jorge Novais defende que a única distinção entre direitos sociais e direitos de liberdade é que a cláusula de aplicabilidade imediata, no Brasil entabulada no $§ 1^{\circ}$ do $\operatorname{artigo} 5^{\circ}$ da Constituição Federal (BRASIL, 1988) ${ }^{2}$, somente se aplica aos últimos. Em tudo o mais, defende o doutrinador português, ambas as categorias de direitos se igualam (NOVAIS, 2006, p. 199). Entretanto, até mesmo esse aspecto diferenciador é rechaçado por Ingo Sarlet, para quem o $\S^{\circ}$ do artigo $5^{\circ}$ da Constituição Federal - e, portanto, a aplicabilidade direta - dedica-se indistintamente a todos os direitos fundamentais, sejam eles de liberdade ou de igualdade (SARLET; MARINONI; MITIDIERO, p. 601).

Isso porque os direitos e garantias fundamentais (gênero do qual são espécies os direitos tanto individuais quanto sociais) guardam, em maior ou menor grau a depender de qual o direito específico em questão, relação com a dignidade da pessoa humana. Ocorre que a dignidade da pessoa não é nada menos do que "o elemento que confere unidade de sentido e legitimidade a uma determinada ordem constitucional" (SARLET; MARINONI; MITIDIERO, p. 266-267).

Assim, os direitos sociais guardam estrita relação com a legitimidade da ordem constitucional, unidos estes elementos pela dignidade humana, que é o fim dos primeiros e a causa da segunda. Logo, qualquer restrição que implique limitação ao exercício dos direitos sociais deve ser analisada criticamente, à luz da potencial afronta à dignidade da pessoa humana que pode advir dessa restrição e da consequente perda da legitimidade do Estado.

Não se pode esquecer, nesse aspecto, que a dignidade da pessoa humana, no Estado de Direito, está "umbilicalmente vinculada" à noção de segurança jurídica, porquanto conceder aos indivíduos a possibilidade de planejarem suas vidas, agir conforme o plano e, ao final, atingirem o resultado desde o início almejado é uma materialização prática de vida digna (SARLET, 2005).

Dessa forma, quando se pretende voltar atrás na implementação de direitos sociais não se pode mais considerar que ocorre apenas ofensa a direitos fundamentais. No Estado

\footnotetext{
2 “§ $1^{\circ}$ As normas definidoras dos direitos e garantias fundamentais têm aplicação imediata."
} 
Democrático e Social de Direito brasileiro, no qual sequer foram implementadas as promessas da modernidade e ainda restam muitos direitos de segunda dimensão a ganharem a mínima efetividade, a discussão em torno da proibição do retrocesso daqueles direitos que tiveram alguma concretização é inadiável (SARLET, 2005). Atos do poder público que impliquem retrocesso na cobertura de direitos sociais devem ser analisados (porque geneticamente relacionados) sob o prisma da dignidade da pessoa humana, da segurança jurídica e dos próprios fundamentos do Estado de Direito.

A segurança jurídica, importante prisma para a análise da redução de prestações sociais não é (mais) a obediência estrita ao texto legal e só ao que consta no texto legal; não é também a qualidade que permite se mande executar todas as prestações garantidoras dos direitos sociais positivados na Constituição Federal; tampouco é um aspecto formalista do direito, não significando a absoluta previsibilidade dos atos do poder público e a impossibilidade de que estes sejam alterados (SARLET, 2005).

Mas, se a segurança jurídica possui indigitada importância, a ponto de estar presente na redação constitucional de maneira direta e indireta, em diversas referências espalhadas ao longo da Carta Maior, isso não se reflete na precisa delimitação de seu sentido e âmbito de aplicação, seja na ordem constitucional brasileira, seja na internacional (SARLET, 2005).

Dada a relevância do tema, para o seu estudo cabe (ao menos tentar) delinear o seu alcance e conceito jurídico.

Conforme a doutrina moderna, a segurança jurídica melhor se traduz em uma sistematização tripartite, incluindo a previsibilidade ou calculabilidade dos comportamentos emanados pelo poder público em qualquer uma de suas esferas (Legislativa, Judiciária ou Executiva), a acessibilidade às decisões dos órgãos públicos no sentido de sua publicidade e coerência, e a estabilidade no que se refere à continuidade dos efeitos das relações jurídicas produzidas no passado. É especialmente essa última acepção que interessa ao presente estudo, uma vez que é ela a face da segurança jurídica violada quando o Estado restringe prestações garantidoras de diretos sociais, porquanto este agir contraria a "tutela de pretensões ou direitos subjetivos, com vistas à preservação de atos, ou de seus efeitos" (MAFFINI, 2017, p. $8-10)$.

Aqui cabe distinguir, para prosseguimento do estudo, as dimensões objetiva e subjetiva da segurança jurídica. Enquanto a primeira corresponde à continuidade do direito e, portanto, à vedação do retrocesso, a segunda alberga a ideia de proteção da confiança 
depositada pelo cidadão nesta continuidade, no que se refere à sua posição jurídica individual e à expectativa de manutenção dos efeitos advindos para ele em decorrência da estabilidade (SARLET, 2005).

Quando se trata da restrição ou redução das prestações garantidoras de direitos sociais, tanto a vedação do retrocesso quanto a proteção da confiança são relevantes. Importa saber, assim, se tal redução apenas na prestação - e não no conteúdo do direito em si representaria afronta à vedação do retrocesso. De outro norte, a confiança do cidadão beneficiado com a prestação restaria desprotegida caso essa fosse reduzida? Ou apenas se fosse totalmente interrompida? ${ }^{3}$

Os defensores da proibição do retrocesso, dentre os quais se destaca J.J. Gomes Canotilho, asseveram que, uma vez regulamentados por legislação infraconstitucional, os direitos fundamentais sociais tornam-se direitos adquiridos dos cidadãos e lhes geram o direito subjetivo a usufruir das prestações públicas tendentes a assegurá-los. Dessa forma, tais prestações não poderiam ser suprimidas sem que houvesse ofensa ao princípio da confiança e, por isso, sairiam da esfera de disponibilidade do legislador, passando a integrar um bloco material que só pode ser modificado para ampliar - e não para reduzir - o padrão geral de prestações já alcançado (SARLET, 2005).

Através desse viés, a inconstitucionalidade de todas as medidas tendentes a reduzir o padrão geral de prestações de direitos sociais já conquistado é defendida por doutrinadores de renome, na medida em que haveria afronta à segurança jurídica, no aspecto da proteção da confiança, e, portanto, afronta ao próprio Estado de Direito.

Ora, o Estado só surgiu e só manteve a sua inquestionável essencialidade em razão da necessidade de organizar expectativas e conceder segurança aos indivíduos. Portanto, a segurança jurídica, embora não esteja expressamente prevista no texto constitucional, já que presente na fundação do Estado, tendo categoria de subprincípio do Estado de Direito, merece ser invocada e respeitada.

\footnotetext{
3 Impõe-se distinguir tal situação, objeto do presente estudo, da concretização de direitos sociais que ainda pendem de medidas estatais que os tornem efetivos. Por sua cristalinidade, mostra-se oportuno transcrever as palavras do professor Ingo Wolfgang Sarlet (2005): "Não se poderá, contudo, confundir o problema da concretização legislativa dos direitos fundamentais sociais - em que pesem suas inequívocas similitudes e seus aspectos comuns - com o da manutenção dos níveis gerais de proteção social alcançados no âmbito do Estado Social, já que esta problemática abrange toda e qualquer forma de redução das conquistas sociais, mesmo quando realizadas única e exclusivamente no plano da legislação infraconstitucional densificadora do princípio da Justiça e do Estado Social que, paralelamente com o princípio do Estado de Direito e com o princípio democrático, encontrou ampla e expressa guarida na nossa Constituição.”
} 
Não menos importante é o argumento do respeito à dignidade da pessoa humana, a qual pode ser afetada em caso de supressão do núcleo essencial legislativamente concretizado de algum direito social (SARLET, 2005). Esse núcleo essencial dos direitos fundamentais sociais é aqui entendido como aquela parcela da prestação social que, acaso subtraída do indivíduo, importaria na perda, por ele, da vida digna. Assim, as prestações básicas sem as quais não se possa garantir a dignidade da pessoa humana, uma vez concretizadas, não podem ser objeto de redução ou supressão, nem mesmo se forem respeitados os direitos adquiridos (SARLET, 2005).

Por outro viés, há quem defenda que, se o legislador, imbuído seja do poder reformador, seja da elaboração da legislação ordinária, pode estabelecer normas que assegurem a prestação de direitos sociais, é natural que ele também possa rever os seus próprios atos e, conforme o orçamento e as prioridades estatais, possa restringir as prestações. Em contraposição, diz-se que dar tal tipo de permissão ao poder reformador significaria darlhe até mesmo o poder de contrariar o poder constituinte originário, tendo-se em vista que por meio da supressão total de prestações de direitos sociais ele teria a faculdade de negar vigência a direito expressamente positivado pelo constituinte (SARLET, 2005).

É inviável sustentar que as leis formuladas por legisladores e os atos administrativos, ainda que restrinjam direitos sociais, representam a vontade da maioria e, portanto, são justos. Tampouco se pode admitir que a legitimação meramente formal de legisladores e administradores, simplesmente porque foram votados para exercer um mandato, habilita-os a reduzir questões de tamanha relevância como direitos fundamentais sociais sem que haja algum tipo de consulta à população representada.

Parece também ser inviável sustentar que as regras de concretização e efetivação dos direitos sociais são regras de livre disposição pelo legislador e pelo administrador público, que poderiam alterá-las ou revogá-las a qualquer tempo, da mesma maneira que o fazem em relação a leis complementares e ordinárias e atos executórios e normativos relativos a outras matérias.

Muito embora os méritos e deméritos de cada uma das posições, nesse estudo opta-se por adotar uma posição moderada. Parece indiscutível viabilizar ao legislador a negativa de eficácia a direitos fundamentais sociais, os quais foram positivados no texto constitucional justamente para que fosse mais penoso restringi-los. Considerando a particularidade dos 
direitos sociais, que só são concretizados mediante prestações estatais normalmente disciplinadas em legislação infraconstitucional, não se mostra razoável permitir que, pelo procedimento ordinário, reduzam-se as prestações e, consequentemente, esvazie-se um direito que, se é que poderia ser modificado, só poderia sê-lo mediante procedimento de emenda à constituição.

Por outro lado, admitir que, uma vez regulamentadas as prestações de direitos, estas só possam ser alteradas para ampliá-las ainda mais também se revela desarrazoado. Ora, semelhantemente a um contrato que pode ser revisto quando, por motivos imprevistos, tornase excessivamente oneroso a uma das partes, também deve ser permitido ao Estado revisitar os seus atos - especialmente aqueles que implicam gastos públicos, como são praticamente todas as prestações garantidoras de direitos sociais - a fim de adequá-los ao momento histórico.

É evidente que mudanças atuais não foram previstas no passado, quando regulamentadas as formas e as exigências para se usufruir de direitos. Entretanto, tendo ocorrido modificações que aumentam a demanda por serviços estatais, gera-se um aumento das contas públicas que, acaso desequilibradas em razão da nova demanda, não só autorizam, como requerem revisão das condições de prestação de políticas públicas a fim de manter o equilíbrio financeiro do Estado.

A não se admitir tal possibilidade, estar-se-á compactuando com a falência financeira do ente público, que possivelmente necessitará de empréstimos externos ou de seus próprios cidadãos para manter os compromissos que assumiu no passado e, muito provavelmente, com um futuro marcado por reformas ainda mais restritivas de prestações efetivadoras de direitos fundamentais sociais, no afã emergencial de retomar o equilíbrio. Assim, não se terá admitido a restrição de direitos fundamentais sociais para, num futuro não muito distante, não ter escolha senão admiti-la, dada a completa inaptidão em que o Estado poderá se encontrar para concretizar os direitos positivados.

Se a escolha deve ser entre reduzirem-se as prestações sociais para prevenir o desequilíbrio financeiro estatal ou para remediar emergencialmente já após a entrada no estado de desequilíbrio, não parece desarrazoado defender a primeira opção. Resta, apenas, desenvolver critérios de controle, para que a supressão de prestações realmente só se torne vantajosa em situações extremas, de verdadeira possibilidade de falência financeira do Estado, desestimulando o seu uso como mero instrumento político para eliminar direitos. 
Que o legislador e os demais agentes públicos, no exercício de sua função, não podem restringir as prestações concretizadoras de direitos fundamentais sociais é quase incontroverso e é o que se defende no presente ensaio. Porém, existem consideráveis discussões, não sem fundamentos, acerca da "amplitude da proteção outorgada pelo princípio da proibição do retrocesso social" (SARLET, 2005).

\section{A PROTEÇÃO RESSARCITÓRIA SIMULTÂNEA DA CONFIANÇA COMO TÉCNICA PARA CONJUGAR A VEDAÇÃO DO RETROCESSO COM A POSSIBILIDADE DE ATOS PÚBLICOS REDUTORES DE PRESTAÇÕES SOCIAIS}

De acordo com a lição do professor Rafael Maffini (2017, p. 10), segurança jurídica é um "elemento identificador e imanente do Estado e do próprio Direito", do qual a proteção da confiança legítima é um aspecto subjetivo. "No sentido objetivo, a segurança jurídica relaciona-se com a previsibilidade dos atos estatais, além de todos aqueles institutos previstos no art. $5^{\circ}$, XXXVI, da CF/88 (ato jurídico perfeito, direito adquirido e coisa julgada).”

Na dimensão subjetiva, da proteção da confiança, caracterizada pela estabilidade que se espera dos atos, procedimentos e condutas estatais, é possível salientar algumas principais áreas de incidência. A primeira, mais identificada com a proteção substancial da confiança, consiste na imposição de limites ao Estado no que se refere à alteração de atos que implique situação desfavorável para o administrado.

A seu turno, a segunda dimensão consiste na proteção procedimental da confiança legítima, consistindo na necessidade de processualização da atividade administrativa, a fim de que seja assegurada a participação dos administrados interessados na tomada da decisão administrativa, especialmente nos casos em que a decisão possa lhe gerar prejuízos.

No entanto, o que aqui desperta principal interesse é a terceira dimensão, consubstanciada na reparação do patrimônio do administrado em decorrência de danos advindos para si da sua confiança nos atos administrativos e na suposição de que estes atos seriam mantidos. É, nas palavras incorrigíveis de Maffini (2017, p. 47-48), “o dever de o Estado reparar danos causados em face da frustração de confiança legitimamente depositada por terceiro em atos estatais" que torna "inegável a responsabilidade civil do Estado por frustração de legítimas expectativas depositadas por terceiros em favor de suas condutas".

Assim, o Estado, ao frustrar confiança legítima do particular, deve ser responsabilizado pelos danos a que o seu ato houver dado causa. Todavia, se é certo que a 
proteção ressarcitória da confiança deve incidir após falhar o aspecto substancial da confiança, questiona-se por que (e se) não se pode utilizar da proteção ressarcitória da confiança simultaneamente, ao mesmo tempo em que praticado o ato que incide contra a segurança jurídica do cidadão.

Ora, ao contrário do que pode parecer, a conduta do Estado (seja através da legislação ou de atos administrativos) não se reveste do dolo de efetivamente prejudicar a confiança nele legitimamente depositada pelos cidadãos. As alterações realizadas frequentemente são motivadas pela necessidade de ajustar orçamentos ou de se adequar às novas demandas sociais, resultantes da evolução natural da sociedade.

Dada a finitude de recursos públicos, quando o Estado passa a atuar em alguma nova área invariavelmente terá de reduzir seu alcance em outra, daí resultando a necessidade de modificar situações sobre as quais recaía confiança legítima de que haveria continuidade e, assim, frustrando a expectativa de seus cidadãos. Como se vê, a ofensa à confiança, sempre que o Estado agir de maneira ideal, é uma consequência inevitável da adequação das proteções às novas demandas da sociedade em geral ou a eventual nova situação orçamentária.

Não se constatando, na ação estatal que atenta contra a confiança, um dolo de assim fazê-lo, não parece irrazoável acreditar que tanto o legislador quanto o agente administrativo possam assumir o compromisso de mitigar, tanto quanto possível, os danos causados aos particulares quando as leis ou atos que produzem afrontarem a segurança jurídica. É claro que não se tem a ingenuidade de acreditar que tal compromisso seria assumido espontaneamente, sem necessidade de instrumentos de coação - situação esta, que, no entanto, foge do objeto do presente ensaio.

Porém, uma vez assumido tal compromisso, a proteção ressarcitória da confiança concedida simultaneamente ao ato ou lei que atentou contra a proteção da confiança em seu aspecto substancial parece se revelar um bom instrumento. O proposto poderia se concretizar com a estipulação de um valor indenizatório destinado a todos aqueles que comprovem terem sido afetados pela alteração legislativa ou administrativa, com o fornecimento de um serviço equivalente ao que fora ofertado ou com medidas que gerassem para o particular o mesmo resultado esperado da medida que fora suprimida.

Especificamente quando se fala em alterações que reduzem as prestações sociais necessárias à dignidade da pessoa humana, esse aspecto ganha ainda mais relevância. Ora, se a pretensão legislativa ou administrativa tem o potencial de afetar o mínimo existencial e 
partindo-se da dificuldade que circunda a determinação prática do que caracteriza o núcleo essencial de um direito e, consequentemente, do que afronta a dignidade da pessoa humana, poder-se-iam evitar longas e inócuas discussões sobre uma valoração um tanto subjetiva por meio da proatividade do Estado.

Essa proatividade consistiria em, ao identificar que um ato (legislativo ou administrativo) possui o potencial de afetar prestações sociais diretamente relacionadas à dignidade da pessoa humana e após (e somente após) retirar do ato todos os aspectos redutores de direitos que são dispensáveis à consecução do objetivo constitucionalmente justificável pelo qual o ato está sendo praticado, dimensionar o conjunto de indivíduos que teriam sua segurança jurídica afetada, prospectar em qual intensidade há a quebra da proteção da confiança ${ }^{4}$ e, ao fim, estabelecer uma forma justa e proporcional de indenizá-lo.

Deve-se ressaltar que essa indenização, contrariamente ao que pode transparecer em um primeiro momento, não necessariamente deve ocorrer através de pecúnia. Consideradas as peculiaridades de cada caso concreto e conforme a natureza do direito fundamental social que estiver sendo objeto de necessário retrocesso, é possível que a garantia da prestação social por mais algum período, sendo reduzida em amplitude com o passar do tempo, numa espécie de transição do estado jurídico anterior ao novo, revele-se muito mais interessante ao particular, além de eficaz sob o ponto de vista da dignidade da pessoa humana, fundamento republicano.

Nessa toada, poder-se-ia falar que as regras de transição, quando proporcionais e razoáveis, caracterizam também uma manifestação da proteção ressarcitória simultânea da confiança, nos moldes em que aqui defendida.

A defesa dessa natureza de ressarcimento é justificada, inicialmente, como não poderia deixar de ser, pelo menor grau de quebra da confiança legítima experimentado pelo cidadão. Quando um indivíduo tem sua confiança legítima frustrada e, só depois de algum tempo, mediante processo judicial, obtém uma reparação pelos danos sofridos, o transcorrer do tempo entre o ato que afrontou sua segurança jurídica e a efetiva reparação faz com que o sujeito vivencie com toda intensidade a quebra da confiança.

Por outro lado, se, no exato momento em que tem conhecimento de que sua confiança fora quebrada, o cidadão também é informado de que estará acobertado por regras de transição, pela continuidade do serviço por um certo período e/ou por indenização

\footnotetext{
4 Aqui, não se pode esquecer do critério sustentado por Ingo Sarlet, no sentido de que "tanto maior deverá ser a garantia da segurança jurídica individual, quanto mais merecedora de proteção for a confiança depositada pelo indivíduo no sistema vigente, proteção esta vinculada também ao fato tempo”. (SARLET, 2005).
} 
pecuniária suficiente, a frustração experimentada será presumidamente muito menor. O cidadão só sentirá a frustração em relação àquilo que não estiver acobertado pelo ressarcimento.

Em suma, se, com a proteção ressarcitória posterior, o sujeito de direitos sofreria a quebra da confiança na extensão total do retrocesso representado pelo ato ou lei em questão, com a proteção ressarcitória simultânea a quebra da confiança sentida será a correspondente ao ato, mas subtraídos os efeitos que forem amenizados pelo ressarcimento imediato. Enquanto a afronta à segurança jurídica no primeiro caso seria representada pelo completo grau de retrocesso do ato, no último o desrespeito à segurança poderia ser traduzido na seguinte fórmula: retrocesso do ato - ressarcimento imediato = afronta à segurança jurídica mitigada.

No caso específico em que o ato legislativo ou administrativo represente uma redução das prestações concretizadoras de direitos fundamentais sociais, esse aspecto adquire ainda maior relevância, uma vez que, partindo-se da ligação estreita entre a garantia de um direito social e a dignidade da pessoa humana que possui direito subjetivo a esta garantia, deve-se buscar que o sujeito sinta os efeitos do ato restritivo na menor intensidade possível, desde o primeiro momento, sob pena de ofensa a vida digna. Nesse aspecto não basta que a ofensa à dignidade seja posteriormente reparada, o importante é que tal ofensa nunca ocorra.

Imagine-se o caso de uma escola de ensino fundamental que é subitamente fechada pelo município, em razão dos altos custos para mantê-la e da baixa quantidade de estudantes que nela estão matriculados, em virtude de sua localização em área isolada e de pouca densidade demográfica. Nessa situação, os alunos seriam transferidos para outra escola, distante cerca de dez quilômetros da que fora fechada, não existindo transporte público que realize o trajeto entre a região em que os alunos residem e a escola para a qual foram transferidos.

Em um caso assim, a proteção ressarcitória tradicional, assegurada mediante processo administrativo ou judicial, caso demorasse mais de um mês para ocorrer (previsão consentânea com a realidade da duração de processos em nosso país e à demora mesmo no cumprimento de medidas liminares), os alunos transferidos ficariam sem condições de frequentar as aulas e perderiam uma carga enorme de conteúdo, que dificilmente seria recuperada após o seu retorno aos bancos escolares. Haveria enorme chance de desempenho insuficiente em provas e, ao final do ano letivo, reprovação; ou seja, a perda de um ano letivo em razão de alguns meses sem proteção jurídica garantida; um enorme prejuízo aos 
estudantes, à sua própria dignidade, em razão do transcurso de tempo entre o ato e o ressarcimento.

Por outro lado, se, no momento em que o ente municipal decidisse pelo fechamento da escola já providenciasse transporte escolar gratuito para que os alunos da escola fechada fossem até a sua nova escola, desde o primeiro dia da transferência, a ofensa ao direito à educação simplesmente não ocorreria. É possível, sim, que algum desconforto adviesse da nova situação, visto que os alunos perderiam mais tempo no deslocamento até a sua escola. Entretanto, unicamente em razão da simultaneidade com que foi apresentada a proteção ressarcitória da confiança, não se poderia sustentar (ressalvados casos excepcionais) nenhum desrespeito a direito fundamental social e, muito menos, à dignidade da pessoa humana.

Dessa forma, resta nítido o alinhamento da proteção ressarcitória simultânea da confiança com a dignidade da pessoa humana, porquanto, em vez de meramente assegurar que a vida digna seja restaurada em algum momento, garante que a dignidade sequer seja afetada.

O segundo argumento para defesa da proteção ressarcitória de forma simultânea tem suas raízes na falta de critérios objetivos para se avaliar, em momento anterior à elaboração do ato administrativo ou legislativo, se o mesmo interfere ou não no núcleo essencial de um direito constitucionalmente previsto. Considerando que o núcleo essencial de um direito social já concretizado não pode ser objeto de restrições na concretização, sob pena de inconstitucionalidade por afronta ao próprio direito e à segurança jurídica, importaria ao legislador e ao administrador terem mecanismos que lhes permitissem, ainda durante o processo de elaboração do ato, conferir com certo grau de certeza, se a medida que se pretende concretizar poderá afetar o núcleo essencial de algum direito ou não.

Ocorre que não existe uma definição segura sobre o que compõe o núcleo essencial de um direito e o que está fora, na esfera de disposição do legislador caso seja necessária uma redução de prestações sociais. Essa definição dependerá de uma valoração a ser feita $a$ posteriori, conforme o caso concreto, e poderá ser tão diferente quanto sejam as experiências de vida e os valores pessoais de cada um dos indivíduos que fará a valoração.

Dessa maneira, ainda que o legislador ou administrador se revista de todas as cautelas e faça uma valoração crítica de seu ato para que ele não caracterize ofensa ao núcleo essencial de um direito fundamental, não serão pequenas as chances de que posteriormente o ato seja questionado e declarado inconstitucional em juízo, haja vista a possibilidade de que o 
juiz valore a situação de forma divergente - já que não existem critérios seguros para essa aferição.

Daí decorre que poucos são os atos administrativos (e, em alguma parcela, os legislativos) elaborados com segurança. $\mathrm{O}$ administrador normalmente tem o receio de que seu ato seja revisto judicialmente e necessita sempre estar preparado para tanto, especialmente sob o aspecto financeiro, caso seja condenado ao cumprimento imediato de alguma decisão judicial que demande despesas ou o retorno ao status quo para que seja restabelecida a segurança jurídica e o estado de confiança.

Caso se adotasse a proteção ressarcitória simultânea da confiança, no entanto, haveria menos empecilhos no que tange à valoração feita antes do ato que se pretende editar e ao planejamento do ente administrativo. Explica-se: a proteção ressarcitória consiste em fornecer ao cidadão potencialmente afetado pelo ato restritivo algo que compense a sua perda. Essa compensação poderá ser tanto pecuniária quanto em serviços prestados pelo Estado ou por terceiros por ele contratados ou ainda de outra forma que pareça adequada à situação em concreto. O importante quando se define qual a modalidade de ressarcimento é que haja alguma semelhança entre o grau de proteção que será retirado do cidadão pelo ato restritivo e o que lhe será concedido mediante proteção ressarcitória simultânea. A verificação da semelhança, no caso prático, mostra-se muito mais fácil e objetiva do que a constatação de ter havido ou não ofensa ao núcleo essencial de um direito fundamental social.

Tome-se como exemplo o mesmo caso da escola que será fechada pelo ente municipal e imagine-se que não foi ofertada aos alunos nenhuma espécie de proteção ressarcitória simultânea (a qual, no caso anterior, foi constituída pelo fornecimento de transporte escolar gratuito a outra escola). Suponha-se também que não há nenhuma lei obrigando o ente público ao fornecimento de transporte escolar gratuito.

Nesse caso, mostra-se bastante possível que alguns defendam que houve afronta ao núcleo do direito à educação, porquanto os estudantes, para frequentar a nova escola distante, teriam de recorrer a fontes alternativas de transporte, dispendendo para isso elevado valor monetário, o que para famílias de menor poder aquisitivo representaria verdadeira impossibilidade de assiduidade à instituição de ensino. Por outro lado, também é possível a sustentação de que não houve afronta ao núcleo do direito à educação, eis que o município permaneceu mantendo uma escola aberta e com vagas disponíveis para os alunos da escola fechada (núcleo do direito), ao passo que o transporte gratuito até a instituição de ensino, embora seja desejável e recomendável, está fora do núcleo essencial do direito à educação. 
Todos podem assumir um lado e defendê-lo nesse debate, mas certo é que critérios objetivos e seguros para resolver qual das duas opiniões deve prevalecer ainda não há.

De outro rumo, uma vez aplicada a proteção ressarcitória simultânea da confiança, o importante seria buscar uma prestação com semelhante grau de proteção social em relação à prestação restringida, o que parece tarefa menos complexa. Em síntese, faz-se uma troca de prestações similares (não necessariamente equivalentes). Prosseguindo no mesmo exemplo dado: troca-se uma escola pública e gratuita próxima à residência dos alunos por uma escola pública e gratuita distante da residência porém com disponibilização de transporte gratuito para ir e voltar dela.

Essa racionalização acerca de como proceder (substituindo prestações semelhantes e não mais valorando aspectos de difícil determinação) guarda em si o potencial de reduzir a discussão e a dúvida sobre ter havido violação à vedação do retrocesso ou não. Acaso realmente reduzida, a consequência lógica é que igualmente reduziriam os processos judiciais em que se questiona a constitucionalidade de atos supostamente lesivos ao núcleo do direito, especialmente aqueles ajuizados por especulação, na esperança de que, no vazio de critérios seguros, o julgador faça valoração contrária à do legislador ou administrador e declare nulo o ato.

Por fim, o terceiro argumento favorável à adoção da proteção ressarcitória em simultâneo guarda estrita relação com o anterior e consiste na possibilidade de o administrador constatar mais facilmente se a medida restritiva que se pretende adotar será realmente mais benéfica aos cofres públicos.

Já se relatou que não existem parâmetros objetivos para se verificar a priori se um ato afronta o núcleo essencial de um direito ou não, ficando o legislador e o administrador a mercê de valorações subjetivas feitas por si e, posteriormente, pelo julgador, caso seu ato seja questionado judicialmente. Igualmente se aduziu que essa incerteza faz com que o administrador necessite estar preparado para uma eventual decisão judicial determinando que volte a prestar os mesmos serviços aos cidadãos ou que os ressarça financeiramente pelos prejuízos experimentados em quantia a ser definida no processo - quantia esta que é desconhecida pelos agentes públicos.

Todavia, com a adoção do critério de substituir uma prestação social por outra com grau similar de proteção do mesmo direito fundamental, o administrador, que já deverá ter em mãos os custos da prestação vigente, poderá efetuar um comparativo com os custos previstos 
da prestação ressarcitória e decidir criteriosamente se vale mais a pena manter a prestação atual ou então reduzi-la e ressarcir as consequências da redução.

Retornemos ao exemplo prático: constatando que a manutenção da escola está sendo deveras custosa ao erário, o administrador pode verificar o custo do transporte gratuito até a escola que receberá os alunos (prestação ressarcitória) e compará-lo com os custos mensais de manter a primeira escola em funcionamento. Sendo menos custoso fornecer o transporte, provavelmente optará pelo fechamento da escola e por transferir seus alunos a outra. Porém, tendo em vista que não se violou o direito à educação com essa medida, possivelmente pouquíssima ou nenhuma demanda judicial seria proposta questionando tal medida, sendo pouco provável que alguma fosse provida.

Por outro viés, se o administrador apenas fechasse a escola e aguardasse até que alguma ação judicial o obrigasse à proteção ressarcitória da confiança em momento posterior, não conseguiria prever os custos dessa proteção, pois os seus termos seriam definidos não por si, mas por um juiz ou tribunal, e a medida provavelmente teria de ser cumprida às pressas, relativizando-se as etapas de planejamento e de busca pelo melhor preço no mercado. Ora, considerando que a administração pública consiste justamente em manejar os recursos públicos de forma a dar-lhes o melhor aproveitamento possível, não há como se defender que esta última opção, na qual não se tem condições de prospectar custos, seja a melhor.

Diante do que foi exposto até aqui, pode-se concluir pela impossibilidade temperada de se elaborarem atos, administrativos ou legislativos que importem redução do padrão geral de prestações sociais mantido até então. Em que pese não se possa querer do Estado uma postura estática, imóvel, tal qual uma estátua (MARTINS-COSTA, 2004, p. 113), igualmente não se pode ser leniente com a ingerência do poder estatal na esfera de direitos subjetivos do cidadão sem que seja realmente demonstrada a necessidade de interferir e reduzir a concretização de tais direitos.

Há, entretanto, considerável dificuldade teórica de se estabelecer um modelo de regras ou parâmetros para verificar se restrições sociais praticadas por entes públicos são legítimas ou estão violando a cláusula de vedação do retrocesso e o princípio da segurança jurídica. A fim de reduzir tal complexidade e render mais estabilidade quanto a uma questão tão importante quanto a efetivação de direitos fundamentais sociais, pode ser adotada a técnica da proteção ressarcitória simultânea da confiança, que não consiste em indenizar o particular pelos danos sofridos em razão da ofensa do Estado à confiança legítima após ser provocado, mas sim no mesmo momento em que decide adotar o ato restritivo. 
É claro que, para que tal técnica seja incorporada e praticada pelos entes públicos, não se pode esperar um fenômeno espontâneo, sendo preciso incorporá-la às regras de direito administrativo e, até mesmo, constitucional - para que seja aplicada também no processo de elaboração de leis. Todavia, partindo-se das vantagens que advêm da utilização de tal técnica (redução de demandas judiciais, maior possibilidade de controle do orçamento público e menor grau de quebra da confiança legítima dos cidadãos), constata-se a existência de motivos suficientes para que ela passe a fazer parte de nosso ordenamento jurídico, como condição e limite para que prestações efetivadoras de direitos sociais possam ser restritas.

Não há dúvidas, assim, de que o princípio da segurança jurídica, que engloba a proteção da confiança, está umbilicalmente conectado ao princípio do Estado de Direito e ao compromisso com a busca pela dignidade da pessoa humana, devendo ser esta o fim último das ações estatais. Nesse contexto, o dever estatal de ressarcir simultaneamente a quebra da confiança legítima dos indivíduos aspira ser instrumento de garantia da dignidade humana e limite a qualquer ato tendente a reduzir prestações sociais.

\section{CONSIDERAÇÕES FINAIS}

Considerando que a segunda dimensão de direitos possui a intenção primeira de orientar e limitar a atuação estatal, no sentido de que seja concretizada a dignidade da pessoa humana, a violação a qualquer das formas de direito por entes públicos deve ser evitada e, caso ocorra, controlada.

Os direitos sociais, por sua característica natural de exigirem dos entes estatais prestações positivas para serem efetivados, estão sujeitos a situação de vulnerabilidade dentro do ordenamento jurídico, uma vez que é possível afrontá-los mediante reduções orçamentárias e normas infraconstitucionais que disciplinem a forma e a extensão de sua aplicação. Para agravar, tal afronta pode ocorrer mascarada pelo texto constitucional, que continuará trazendo em si extenso rol de direitos sociais, embora inefetivados pela ausência de dispositivos infraconstitucionais que os concretizem.

Dada a recorrência dos discursos políticos voltados à redução de prestações sociais como bode expiatório para a crise econômico-financeira que se vivencia atualmente em diversas nações, a matéria ganha importância contemporânea e clama por soluções norteadoras das medidas redutoras de direitos fundamentais sociais que se pretende implementar.

Rev. de Direito Sociais e Políticas Públicas | e-ISSN: 2525-9881 | Porto Alegre | v. 4 | n. 2 | p. 56 - 75 | Jul/Dez. 2018 
Em que pese a inexistência de um critério seguro para aferir qual é o limite da restrição de prestações sociais sem que tal redução implique violação dos direitos sociais em sua substancialidade, uma vez que a discussão se insere no contexto do Estado Democrático de Direito, marcado pelo princípio estruturante da segurança jurídica, a esta se pode recorrer para procurar resolver a questão.

Os desdobramentos da segurança jurídica, em especial a proteção da confiança legítima e os desdobramentos desta, em específico a proteção ressarcitória simultânea, podem ser guias na elaboração de atos administrativos ou legislativos tendentes a reduzir prestações sociais, motivando que estes, paralelamente, gerem a menor quebra de confiança possível para com os cidadãos.

Não há que se optar por um discurso favorável somente aos cidadãos ou somente ao Estado. Considerando que o último só existe em razão dos primeiros e que deve se orientar segundo as demandas e necessidades destes, a opção por uma técnica que encontre as expectativas de ambos se revela uma alternativa desejável.

Dessa forma, defende-se a proteção ressarcitória simultânea da confiança como forma de obter o comprometimento estatal com a não violação de direitos sociais, do princípio da segurança jurídica e da vedação do retrocesso, em troca da possibilidade de melhor planejamento orçamentário, de redução de demandas judicias e de maior grau de liberdade da elaboração de seus atos sem, como não poderia deixar de ser, interferir na vida digna de seus cidadãos.

\section{REFERÊNCIAS}

BRASIL. Constituição (1988). Constituição da República Federativa do Brasil de 1988. Brasília, DF, Disponível em: <http://www.planalto.gov.br/ccivil_03/constituicao/constituicaocompilado.htm>. Acesso em: 25 jun. 2018.

CALMON DE PASSOS, J. J. Democracia, participação e processo. In: GRINOVER, Ada Pellegrini; DINAMARCO, Cândido Rangel; WATANABE, Kazuo. Participação e Processo. São Paulo: RT, 1988, p. 83-97.

CANOTILHO, José Joaquim Gomes. Direito constitucional. 5. ed. Coimbra: Almedina, 1992.

LAFER, Celso. A reconstrução dos direitos humanos: um diálogo com o pensamento da Hannah Arendt. São Paulo: Companhia das Letras, 1988. 
MAFFINI, Rafael. Princípio da proteção da confiança legítima. In: NUNES JÚNIOR, Vidal Serrano et al. Enciclopédia jurídica da PUCSP. São Paulo: Pontifícia Universidade Católica de São Paulo, 2017. t. 2: direito administrativo e constitucional. Disponível em: $<$ https://enciclopediajuridica.pucsp.br/verbete/120/edicao-1/principio-da-protecao-daconfianca-legitima>. Acesso em: 29 maio 2018.

MARTINS-COSTA, Judith. A re-significação do princípio da segurança jurídica na relação entre o estado e os cidadãos: a segurança jurídica como crédito de confiança. Revista CEJ, Brasília, n. 27, p. 110-120, out./dez. 2004. Disponível em: <http://www.jf.jus.br/ojs2/index.php/revcej/article/viewFile/641/821>. Acesso em: 18 jul. 2018.

NOVAIS, Jorge Reis. Direitos fundamentais: trunfos contra a maioria. Coimbra: Coimbra, 2006.

PIOVESAN, Flávia. Direitos humanos e o direito constitucional internacional. 14 ed. rev. e atual. São Paulo: Saraiva, 2013.

SARLET, Ingo Wolfgang; MARINONI, Luiz Guilherme; MITIDIERO, Daniel. Curso de Direito Constitucional. 6 ed. rev. e atual. São Paulo: Saraiva, 2017.

SARLET, Ingo Wolfgang. A eficácia do direito fundamental à segurança jurídica: dignidade da pessoa humana, direitos fundamentais e proibição de retrocesso social no direito constitucional brasileiro. Revista Brasileira de Direito Público, Belo Horizonte, v. 3, n. 11, p. 11-156, out./dez. 2005. Disponível em: <http://www.direitodoestado.com.br/artigo/ingowolfgang-sarlet/a-eficacia-do-direito-fundamental-a-seguranca-juridica-dignidade-da-pessoahumana-direitos-fundamentais-e-proibicao-de-retrocesso-social-no-direito-constitucionalbrasileiro>. Acesso em: 30 jun. 2018.

VILLIERS, Bertus de. The socio-economic consequences of directive principles of state policy: limitations of fundamental rights, 1992. 